\title{
Carbon Sequestration Potential of Teak Plantations of Different Agro-Climatic Zones and Age-Gradations of Southern India
}

\author{
MILKURI CHIRANJEEVA REDDY ${ }^{1}$, R. M. PRIYA ${ }^{1}$ and S. L. MADIWALAR ${ }^{2}$ \\ College of Forestry, DrY S Parmar University of Horticulture and Forestry, India \\ ${ }^{2}$ College of Forestry, UAS, Dharwad, India. \\ http://dx.doi.org/10.12944/CWE.9.3.27
}

(Received: October 28, 2014; Accepted: October 19, 2014)

\begin{abstract}
Carbon sequestration potential of teak plantations in different agro-climatic zones of Southern India, viz. Northern Dry Zone, Northern Transition Zone, and Hilly Zone were studied. Teak plantations belonging to three age gradations viz. 10, 15 and 20 years were considered for the study. Above ground biomass was computed based on volume estimation and wood density after considering three $10 \times 10 \mathrm{~m}$ plots. Carbon sequestration potential of teak plantations on farmlands differed significantly with respect to agro-climatic zones and age. Teak plantations raised on the farmlands of Northern Transition Zone had significantly higher above ground biomass than that in Northern Dry Zone and Hilly Zone at all the three age-gradations. Consequently, total above ground carbon sequestered was also significantly higher among the teak plantations of the Northern Transition Zone (247.47 t/ ha) than that in Hilly Zone (157.60 t/ha) and NDZ (103.73 t/ha). For obvious reasons total amount of carbon sequestered was significantly higher in 20-year plantations (330.00 t/ha) than in 15-year (108.53 t/ha) and 10-year plantations (70.27 t/ha). Perhaps optimal average annual rainfall of 749 $\mathrm{mm}$ and medium black soil in Northern Transition Zone have contributed to the higher biomass in teak. Poor rainfall in Northern Dry Zone $(<585 \mathrm{~mm})$ and poor soil conditions (lateritic formations) in Hilly Zone must have contributed to the poorer growth of teak in these zones.
\end{abstract}

Key words: Teak, Carbon sequestration, Biomass, Farmlands.

\section{INTRODUCTION}

Indiscriminate deforestation in tropical world has become a major cause of increased carbon dioxide concentration in our atmosphere, It was eported that the global average of the gross emission rate of tropical deforestation was 2.9 petagrams of carbon (Pg C y-1) from 1990 to 2007 and that tropical regrowth forests were partially compensated for by a carbon sink of $1.6 \mathrm{Pg} \mathrm{C}$ $y-1$ within an area of 557 Mha. ${ }^{12}$. For combating this series environmental issue continuous efforts are been made by international community by promote several actions for reducing emissions from deforestation and forest degradation (REDD) in the international society, one important example of which is afforestation in deforested areas ${ }^{3}$ along with several international conventions and conferences which were brought to life such as United Nations Framework Convention on Climate Change (UNFCCC) in 1992 to stabilize GHG concentration in the atmosphere, Kyoto protocol in 1997, CoP 7 of UNFCCC in $2001^{4}$ etc.

Tectona grandis Linn. $\mathrm{F}$ is a valuable timber yielding species which is rated for its durability, mellow color, and long straight cylindrical bole belongs to the family Lamiaceae being grown in plantations in around 60 countries in Asia, Africa and Latin America although its natural occurrence is limited to India, Laos, Myanmar and Thailand. Of the estimated 142 million hectares of global plantations 
in 2005 ,about 5.82 million hectares (4\%) were teak plantations. Teak constitutes about $75 \%$ of the world's high-quality tropical hardwood plantations ${ }^{5}$.

Improved land management could result in store substantial amount of soil carbon and prevent this culprit gas from entering into our atmosphere ${ }^{6}$. Tree plantations are capable of sequestering greater quantity of carbon within their main stem wood, bark, branches, foliage and roots and soil while carbon sequestered by the main stem wood results in longer sequestration while other components sequester and release carbon on shorter intervals due to natural pruning and decomposition (7). Carbon sequestration potential of tree species becomes relevant in this respect.

Primary productivity and biomass gain which are directly proportionate to carbon stored in a plant or an ecosystem varies with the availability of resources and characteristics of the environment

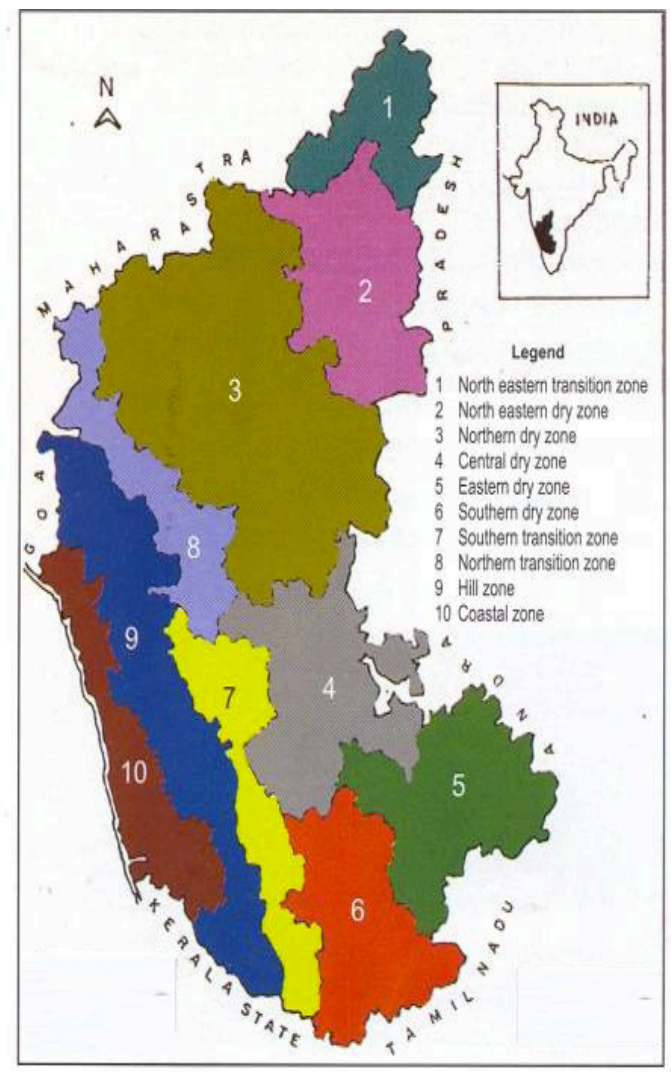

Fig. 1: Map showing different agro-climatic zones of Karnataka selected for study in which they grow. Strongest ecological factors like climate and age influences primary productivity of a species or ecosystem thus changes in climate $\&$ age can cause changes in amount of carbon sequestered. Keeping these points in view a study was conducted to understand carbon sequestration potential of teak in different agro-climatic zones and age gradations.

\section{Material and methods}

The present study was conducted in three different agro-climatic zones of Karnataka i.e. Northern Dry Zone ( $14^{\circ} 39^{\prime}$ to $17^{\circ} 24^{\prime} \mathrm{N}$ latitude and $74^{\circ} 34^{\prime}$ to $77^{\circ} 04^{\prime}$ E longitudes), Northern Transition Zone ( $14^{\circ} 13^{\prime}$ to $16^{\circ} 41^{\prime} \mathrm{N}$ latitude and $74^{\circ} 13^{\prime}$ to $75^{\circ}$ $38^{\prime}$ E longitude) and Hilly Zone ( $11^{\circ} 56^{\prime}$ to $15^{\circ} 46^{\prime} \mathrm{N}$ latitude and $74^{\circ} 31^{\prime}$ to $76^{\circ}$ and $76^{\circ} 45^{\prime} \mathrm{E}$ longitude.) (Fig.1) for understanding the carbon sequestrating potential of teak plantations. In each of the climatic zones, teak plantations of three age gradations i.e. 10, 15 and 20-year were chosen for the study. The soils in Northern Dry zone and Northern Transition zone are quite similar. The major soil types in these two zones are mostly medium black soils to shallow black soils. Whereas, in Hilly Zone, red sandy loam, lateritic and medium black soils are predominant. Three Agro-climatic zones were considered as main plots and three age gradations in each of the agroclimatic zones were taken as sub plots. Thus there were three 3 main plot and 3 sub plot treatments.

Average data per hectare was calculated. The total above ground biomass of the tree was expressed as a product of total volume and wood density. Total bole volume was considered as 56, 62 and 63 per cent at 10, 15 and 20-year trees respectively and rest of the above ground biomass was calculated by using standards ${ }^{8}$. Based on the mean total biomass per tree, total above ground biomass per hectare was calculated.

The above ground biomass of standing trees was estimated to work out the amount of carbon sequestered by reducing the total biomass yield to its 50 per cent ${ }^{9}$. Fisher's method of analysis of variance and interpretation of data was applied (10). The level of significance used was $p=0.05$. The mean values of main plots, sub plots were subjected to M-STAT- C program on a computer. 


\section{RESULTS}

Total amount of carbon sequestered per hectare differed significantly due to agro climatic zones and age gradations (Fig. 2). It was significantly higher in Northern Transition Zone (247.47 t/ha) than in Northern Dry Zone (103.73 t/ha) and Hilly Zone (157.60 t/ha). The total amount of carbon sequestered was higher in Northern Transition Zone to an extent of 138.5 and 57.1 per cent over Northern Dry Zone and Hilly Zone respectively. Subsequently total amount of carbon sequestered was significantly higher in 20-year plantations (330.00 t/ha) than in 15 year (108.53 t/ha) and 10 year plantations (70.27 $\mathrm{t} / \mathrm{ha}$ ). The extent of increase of total tree volume in 20-year plantation was 204.1 and 369.6 per cent over 15 year and 10 year respectively.

There was a significant effect shown by interaction between agro climatic zones and age gradations on total amount of carbon sequestered. In case of 10 and 15-year age gradations, amount of carbon sequestered per hectare in Northern Dry Zone (62.2 and $89.90 \mathrm{t} / \mathrm{ha}$ ) was statistically par with that in Hilly Zone (65.20 and $91.40 \mathrm{t} / \mathrm{ha}$ ). Whereas, plantations of 20 year recorded significantly higher amount of carbon sequestered in Hilly Zone (316.20 t/ha) compared to Northern Dry Zone (159.10 t/ ha).

\section{DISCUSSION}

Unlike in developed countries, developing countries do not have carbon inventories and data bank to monitor and enhance carbon sequestration potential of different plantations. Very few attempts were made so far to assess the carbon sequestration in teak plantations with respect to different agroclimatic zones and age gradations in India in general and Karnataka in particular. Therefore, a pilot study was taken up to estimate the above ground carbon sequestrating potential of teak plantations in Karnataka.

The higher amount of carbon sequestrated in Northern Transition Zone can be attributed to higher total above ground biomass in Northern Transition Zone (517.22 t/ha) than in Northern Dry Zone (207.89 t/ha) and Hilly Zone (320.67 t/ha) which in turn was due to favorable soil and climatic conditions. Northern Transition Zone is characterized by moderate mean annual rainfall $(749 \mathrm{~mm})$, higher soil fertility status, lesser temperature extremes. On the contrary, although annual rainfall is much higher in Hilly Zone, the soils are acidic and relatively less fertile. Similarly in Northern Dry zone, although teak plantations were established with protective irrigation, the soils are alkaline and temperature extremes are higher thus lower the amount of carbon sequestrated.

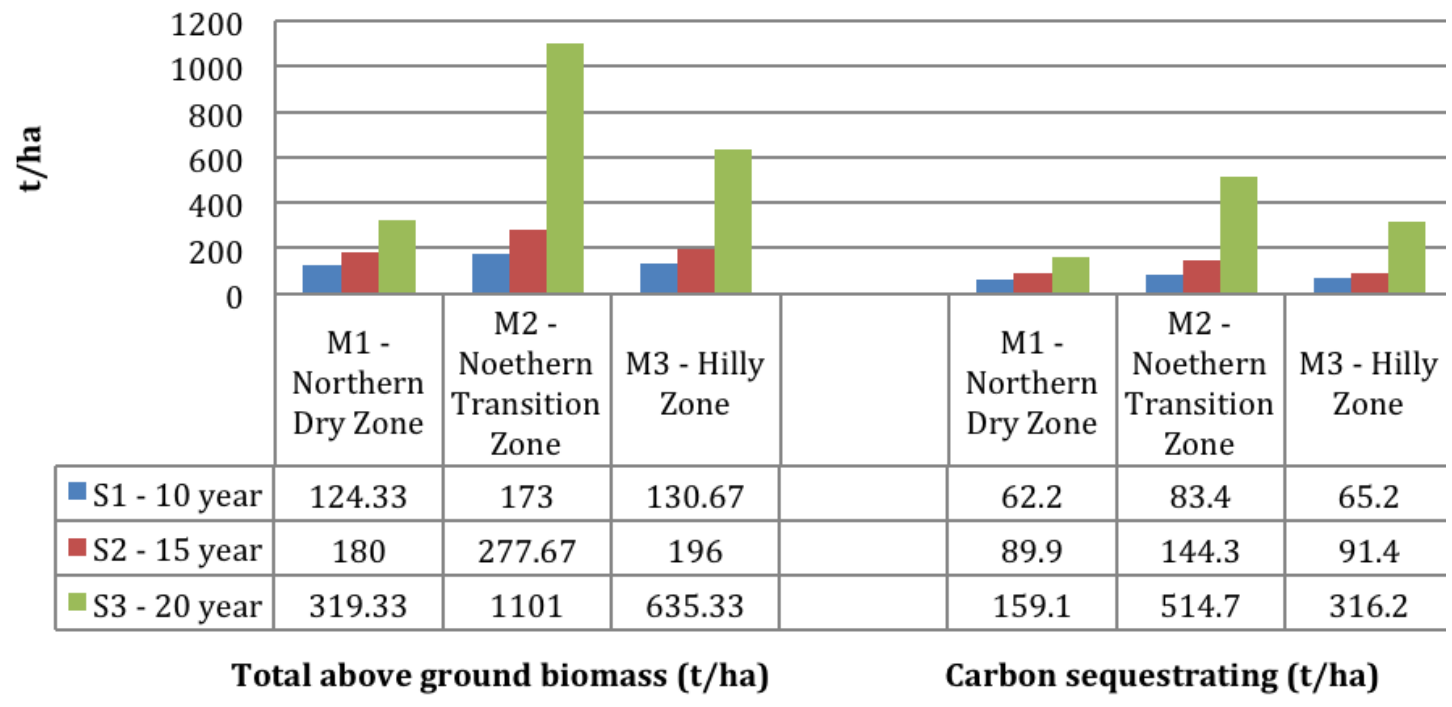

Fig. 2: Total above ground biomass (t/ha) and carbon sequestered (t/ha) in teak plantations as influenced by agro climatic zones and age gradations 
The extent of increase of total above ground biomass in 20-year plantation was 214.5 and 380.3 per cent over 15-year and 10-year respectively (Fig. 2). It might be because of the fact that increment in tree biomass is directly proportional to the increment in age. It was also reported that species level carbon sequestration of teak was done in Panama and revealed that teak plantations contain 351 tons of ' $\mathrm{C}$ '/ ha at the end 20-year rotation period under tropical conditions (11). Similarly biomass in Eucalyptus tereticornis varied from $11.9 \mathrm{t} / \mathrm{ha}$ in three-year old plantation to $146 \mathrm{t} / \mathrm{ha}$ in 9 -year old plantation (12).

The total amount of carbon sequestered in teak plantations was higher in Northern Transition Zone, which was almost double than that of Northern Dry Zone and Hilly Zone at twenty years. Total biomass estimations thus amount of carbon sequestered were made by using volume table models. However more comprehensive studies on biomass estimations of the species under varied agro climatic conditions are required to workout carbon sequestration potential with grater accuracy. Further establishing teak plantations can be extrapolated to the other areas similar to the Northern Transition Zone and a wide array of successive age groups may be considered with in the same site conditions for further study in order to ascertain the major factors influencing the carbon sequestrating potential. This information generated can be used in planning carbon trading in near future.

\section{ACKNOWLEDGEMENT}

We are highly obligated to take this opportunity to thank University of Agricultural Sciences, Dharwad for cultivating opportunity to conduct this study.

\section{REFERENCES}

1. Pan Y. Birdsey R. A. Fang J. Houghton R. Kauppi P. E. Kurz W A. Phillips O. L. Shvidenko A. Lewis S. L. Canadell J. G. Ciais P. Jackson R. B. Pacala S. W. McGuire A. D. Piao S. Rautiainen A. Sitch S. and Hayes D., Science, 333, 988-993, (2011).

2. Masamichi T. Dokrak M. Samreong P. and Keizo H., Dr Juan A. Blanco (Ed.), ISBN: 978-953-51-0202-1, (2012).

3. Gibbs H. K. Brown S. Niles J. O. and Foley J. A., Environmental Research Letters 2, 045023. ISSN 1748-9326. Retrieved from http:// dx.doi.org/10.1088/1748- 9326/2/4/045023, (2007).

4. Murthy I.K. Gupta M. Tomar S. Munsi M and Tiwari R., J Earth Sci Climate Change 4: 131. doi:10.4172/2157-7617.1000131, (2013).

5. Reddy M. C. and Madiwalar S. L., Ind For, 140(3) : 287-290, (2014).
6. Yadav R., Int. J. Env. Sci. 2(3), 1380-1385 (2012).

7. Zeng N., Carbon Balance and Management, 10.1186/1750-0680-3-1 (2008).

8. Jha K. K. Teak (Tectona grandis) Farming A Textbook, International Book Distributors Company, Uttara Pradesh, India, (1999).

9. Kiyono Y. Furuya N. Sum T. Umemiya C. Itoh E. Araki M. and Matsumoto M., Japan Agri Res Quarterly 44, 81-92. ISSN 0021-3551, (2010).

10. Snedecor G. W. and Cochran W. G., Statistical Methods, Oxford and IBH Publications, New Delhi, (1967).

11. Margaret K. Alvaro C. Tim M. and Catherine P., For Eco \& manag, 172 : 213-225, (2003).

12. Rawat V. and Negi J. D. S., Ind For, 130(7): 762-770, (2004). 